\title{
El PENSAMIENTO GRAMATICAL DE BELLO \\ Trabajos presentados en el I Simposio \\ de la Cátedra Andrés Bello \\ (28-29 de noviembre de 2013)
}

\section{Presentación}

\author{
Dario Rojas* \\ Universidad de Chile, Chile \\ Coordinador del simposio
}

La Cátedra Andrés Bello en Humanidades, Ciencias Sociales, Artes, Ciencias de la Comunicación y Ciencias Naturales fue creada el 29 de noviembre de 2012 para conmemorar los 231 años del nacimiento del primer rector de la Universidad de Chile. La Cátedra tiene por objetivo propiciar tanto el desarrollo de los estudios bellistas en nuestro país como el conocimiento en las áreas del saber cultivadas por el insigne pensador chileno-venezolano: la filosofía, la lingüística, la literatura, el derecho, la filología, la historia, el periodismo y, más ampliamente, las humanidades y las ciencias sociales. Junto con ello, la Cátedra busca ser un punto de encuentro que favorezca los estudios interdisciplinarios en humanidades, ciencias sociales, artes, ciencias de la comunicación y ciencias naturales, con especial atención a los temas y problemas nacionales y latinoamericanos. A través de sus actividades, la Cátedra promueve el conocimiento y la reflexión sobre la figura y obra de Bello, fomenta la cooperación intelectual pluridisciplinaria entre los académicos de la Universidad de Chile y otras instituciones de investigación y educación superior e impulsa la difusión del conocimiento bellista a través de diferentes medios, como publicaciones, coloquios y sitios electrónicos.

* Para correspondencia, dirigirse a: Darío Rojas (darioroj@u.uchile.cl), Universidad de Chile, Facultad de Filosofía y Humanidades, Departamento de Lingüística, Av. Capitán Ignacio Carrera Pinto 1025, Ñuñoa, Santiago, Chile. 
El I Simposio de la Cátedra Andrés Bello tuvo por tema general "Bello: lenguaje y cultura de la emancipación" y se realizó los días 28 y 29 de noviembre de 2013 en la Sala Luisa Arce del Archivo Central Andrés Bello de la Universidad de Chile. El objetivo de este primer simposio fue congregar a un grupo selecto de especialistas en la obra de Bello con el fin de analizar y debatir, desde diversas disciplinas y enfoques, sus aportes a los estudios lingüísticos, culturales y humanísticos. La convocatoria encontró favorable acogida entre estudiosos provenientes de Chile, Venezuela, Costa Rica, España, Alemania y Estados Unidos. La actividad fue patrocinada por la Facultad de Filosofía y Humanidades de la Universidad de Chile, la Iniciativa Bicentenario Juan Gómez Millas de esta misma universidad, la Academia Chilena de la Lengua, la Academia Venezolana de la Lengua y el Centro Stanford Chile. La comisión organizadora fue presidida por el profesor Alfredo Matus y estuvo integrada por los profesores María Eugenia Góngora, Iván Jaksic y Fernando Lolas. La coordinación estuvo a cargo de Darío Rojas.

En esta sección monográfica del Boletín de Filología presentamos una selección de los textos leídos en el simposio. En primer lugar, las palabras inaugurales del presidente de la comisión organizadora, Alfredo Matus Olivier: "Pidiendo un Bello desde dentro". A continuación, la Conferencia Anual Andrés Bello 2013, "El diccionario y los diccionarios en la obra de Andrés Bello. Teoría, crítica y elaboración lexicográficas", de Francisco Javier Pérez, catedrático de la Universidad Católica Andrés Bello y presidente de la Academia Venezolana de la Lengua. Antes de la conferencia, Alfredo Matus Olivier pronunció una laudatio en homenaje al conferencista, que en esta ocasión incluimos como prolegómeno.

Luego presentamos un conjunto de trabajos leídos en una de las mesas redondas del simposio, "El pensamiento gramatical de Bello", de autoría de los lingüistas Andrés Gallardo, Nelson Cartagena y Guillermo Soto. Finalmente, añadimos a esta sección un trabajo del bellista estadounidense Barry L. Velleman, que originalmente fue leído a manera de comentario de la conferencia de Francisco J. Pérez.

Agradecemos a los autores la gentileza de haber aceptado nuestra sugerencia de publicar sus trabajos en esta sección monográfica del Boletín de Filología. 